\title{
Disability assessment as a measure of progress in leprosy control
}

\author{
W C S SMITH* \& S M PARKHE† \\ * Cardiovascular Epidemiology Unit, Ninewells Hospital and Medi- \\ cal School, Dundee DDI 9SY; † Belgaum Leprosy Hospital, \\ Vengurla Road, Hindalga-591108, Belgaum District, Karnataka, \\ India.
}

\section{Accepted for publication 8 January 1986}

\begin{abstract}
Summary Leprosy control programmes using methods of secondary prevention are in widespread use throughout the world. It is suggested that the most relevant method of assessing progress is by measuring the prevalence and incidence of disability. Disability assessment (WHO criteria) has been carried out in a control programme in India at baseline and now 4 years later. There has been little change in the prevalence of leprosy over this period but the prevalence of disability has fallen from 91.4 to 62.3 per 100,000 . It is likely that this fall is the result of the control programme since there is no evidence of a secular trend of reduced disability in leprosy in India. The mechanism of this fall is thought to be the loss of disabled patients through death and migration; these are not being replaced by new disabled patients.
\end{abstract}

\section{Introduction}

Leprosy control programmes using methods of secondary prevention are conducted throughout the world. These programmes are based on early detection of disease using a variety of methods and on early, regular, and adequate chemotherapy. It is well recognized that such methods are unlikely to eradicate leprosy $y^{1,2}$ and apart from a few exceptions ${ }^{3}$ control programmes have had little effect on the incidence of leprosy. ${ }^{4}$ This being so, it is therefore important to evaluate leprosy control programmes using a more realistic objective.

The strategy of leprosy control programmes is unlikely to have any significant effect on disease incidence but is more likely to affect disease severity and the level of disability caused by leprosy. A more realistic objective by which to measure the effect of a leprosy control programme would be to ask whether or not it is affecting the disability caused by leprosy. Since the problem of leprosy to the 
individual and society is disability, disability is an appropriate measure of a programme's effectiveness.

This ongoing study examines the effectiveness of one leprosy control programme in India using the point prevalence of disability as the criterion in a defined community. The baseline disability prevalence results have been reported ${ }^{5}$ and we report here the disability prevalence using the same methodology in the same community 4 years later.

\section{Methods}

The defined population for the study was resident in 126 villages in two talukas of Belgaum District in Karnataka State, India with a population of 233,581 at the 1971 census. The leprosy control programme was carried out according to the guidelines of the National Leprosy Control Programme of the Government of India ${ }^{6}$ and staffed to the appropriate level. The programme was carried out by population enumeration and examination by households, schools and contact surveillance. Health education was provided as part of the programme at a variety of levels from schools to village leaders.

Patient management was aimed at maintaining the patient within the community. Treatment was based on oral dapsone, although multidrug therapy has now been introduced, disability management and treatment of reactional states as and when they arose. Patients with anaesthetic limbs were taught preventive care, microcellular rubber chappels were offered and walking plasters were used for plantar ulcers when appropriate. Patients who developed acute disability were hospitalized and given appropriate treatment including physiotherapy and practical health education.

Disability assessment was performed at detection and then at regular intervals usually by the physiotherapy technician. The assessment used was that proposed in 1971 for use in epidemiological surveys, ${ }^{7}$ the assessment being summarized in the Disability Index 2(DI-2). The prevalence of leprosy and its resultant disability had been calculated in 1979 at the end of the first survey and this is compared with the similar findings at the end of the second survey in 1983.

The calculation of the prevalence rate in 1979 is based on the cases detected and the population examined. However, the calculation of prevalence in 1983 is based on existing cases as at the end of December 1983 and therefore includes cases detected during both surveys but excludes those dying, migrating or diseasearrested; this is the true point prevalence rate and not the second survey case detection rate. The denominator in the calculation of the 1983 prevalence is all those examined in either survey. Point prevalence in 1979 is compared with the point prevalence in 1983. Incidence rates can be calculated between 1979 and 1983 but not the change in incidence rates; this can be examined following the third survey. The definition of a case of leprosy includes both active and inactive cases 
but excludes those whose disease is arrested; however the definition of disability includes all those with disability due to leprosy irrespective of whether or not the disease is arrested.

\section{Results}

The population of the defined project area increased by $5.9 \%$ between the two surveys (Table 1). The increase in the number of children $(8.8 \%)$ was much higher than that for adults $(4.1 \%)$. The percentage of the population examined at each survey was $80 \%$ with the rates being higher in children than adults and higher in women than in men (Table 2).

In the first survey 931 cases were detected and a further 703 new cases in the second survey. The classification of cases detected in both surveys is shown in Table 3, the distribution of cases by classification was statistically different in the second survey compared with the first. In the second survey $76 \%$ of cases were at the tuberculoid end of the spectrum compared with $61 \%$ in the first survey. The

Table 1. Age and sex structure of population enumerated at first and second surveys.

\begin{tabular}{lccccc}
\hline & \multicolumn{4}{c}{ Males } & \multicolumn{3}{c}{ Females } & \\
Survey & $0-14 \mathrm{yr}$ & $15 \mathrm{yr}+$ & $0-14 \mathrm{yr}$ & $15 \mathrm{yr}+$ & Total \\
\hline First & 47844 & 78658 & 42767 & 70630 & 239899 \\
& $(19 \cdot 9 \%)$ & $(32 \cdot 8 \%)$ & $(17 \cdot 8 \%)$ & $(29 \cdot 4 \%)$ & \\
Second & 51363 & 81106 & 47180 & 74296 & 253945 \\
& $(20 \cdot 2 \%)$ & $(31.9 \%)$ & $(18 \cdot 6 \%)$ & $(29 \cdot 3 \%)$ & \\
$\begin{array}{l}\text { \% age } \\
\text { change }\end{array}$ & $+7 \cdot 4$ & $+3 \cdot 1$ & $+10 \cdot 3$ & $+5 \cdot 2$ & $+5 \cdot 9$ \\
\hline
\end{tabular}

( ) Figures in brackets are percentages of the totals.

Table 2. Percentage of the population examined in the two surveys by age and sex.

\begin{tabular}{lccccc}
\hline & \multicolumn{2}{c}{ Males } & \multicolumn{3}{c}{ Females } \\
Percentage & $\begin{array}{c}\text { Children } \\
\text { examined }\end{array}$ & Adults & Children & Adults & \\
& $0-14 \mathrm{yr}$ & $15 \mathrm{yr}+$ & $0-14 \mathrm{yr}$ & $15 \mathrm{yr}+$ & Total \\
\hline First survey & $87 \cdot 8$ & $67 \cdot 3$ & $89 \cdot 9$ & $82 \cdot 1$ & $79 \cdot 8$ \\
Second survey & $87 \cdot 4$ & $70 \cdot 1$ & $89 \cdot 1$ & $83 \cdot 5$ & $81 \cdot 1$ \\
\hline
\end{tabular}


Table 3. Leprosy cases detected in the two surveys by classification (Ridley-Jopling).

\begin{tabular}{lcc}
$\begin{array}{c}\text { Type of } \\
\text { leprosy }\end{array}$ & $\begin{array}{c}\text { Number in } \\
\text { 1st survey }\end{array}$ & $\begin{array}{c}\text { Number in } \\
\text { 2nd survey }\end{array}$ \\
\hline I & $172(18 \cdot 5 \%)$ & $115(16 \cdot 4 \%)$ \\
TT & $391(41 \cdot 9 \%)$ & $379(53 \cdot 9 \%)$ \\
BT & $178(19 \cdot 1 \%)$ & $153(21 \cdot 8 \%)$ \\
BL & $51(5 \cdot 5 \%)$ & $30(4 \cdot 3 \%)$ \\
LL & $139(14 \cdot 9 \%)$ & $26(3 \cdot 7 \%)$ \\
\hline Total & 931 & 703 \\
\hline
\end{tabular}

$$
\chi^{2}=64 \cdot 29 ; P<0 \cdot 001
$$

relative importance of the various methods of case detection were very different between the surveys as is shown in Table 4; with both school survey and contact surveillance being more important. The proportion of disabled cases in the second survey was only $5.5 \%$ compared with $18.8 \%$ in the first survey. Many (19 out of 39) of the disabled patients detected in the second survey had not been previously examined. In the first survey 175 patients with disability were detected. Of these 118 remained within the control programme while the rest, 57, had either died or migrated.

\section{Prevalence of leprosy}

The prevalence of leprosy after the first survey in 1979 was 4.86 per 1000 , and the prevalence of leprosy in 1983 at the end of the second survey was $4 \cdot 3$ per 1000 . The

Table 4. Number of leprosy cases detected using different methods in the two surveys.

\begin{tabular}{lrrrr}
\hline \multirow{2}{*}{$\begin{array}{l}\text { Detection } \\
\text { method }\end{array}$} & \multicolumn{2}{c}{ First survey } & \multicolumn{2}{c}{ Second survey } \\
& number & $(\%)$ & number & $(\%)$ \\
\hline $\begin{array}{l}\text { General survey } \\
\text { School survey }\end{array}$ & 630 & $(67 \cdot 7)$ & 404 & $(57 \cdot 5)$ \\
Contact survey & 26 & $(2 \cdot 0)$ & 65 & $(9 \cdot 2)$ \\
Voluntary & 256 & $(27 \cdot 5)$ & 158 & $(10 \cdot 8)$ \\
\hline Total & 931 & & 703 & \\
\hline
\end{tabular}

$$
\chi^{2}=92 \cdot 28 ; P<0.001
$$


prevalence of leprosy in 1983 is not the case detection rate at the second survey but includes patients detected during the first survey who were still under treatment in 1983. There were 931 cases detected during the first survey but, by $1983,72 \mathrm{had}$ died, 349 were disease arrested and 165 had emigrated.

The prevalence of the different classifications of leprosy in 1979 and 1983 are shown in Table 5. There is a fall in the prevalence of indeterminate and lepromatous leprosy but little change in the other types.

The prevalence of leprosy in the age and sex groups is shown in Table 6. Both adult prevalence rates show a fall while the prevalence rates in children of both sexes have risen.

Table 5. Prevalence of leprosy by classification in 1979 and 1983

\begin{tabular}{|c|c|c|c|c|}
\hline \multirow[b]{2}{*}{ Classification } & \multicolumn{2}{|c|}{1979} & \multicolumn{2}{|c|}{1983} \\
\hline & $\begin{array}{l}\text { Number } \\
\text { of cases }\end{array}$ & $\begin{array}{l}\text { Prevalence } \\
\text { per } 1000\end{array}$ & $\begin{array}{l}\text { Number } \\
\text { of cases }\end{array}$ & $\begin{array}{c}\text { Prevalence } \\
\text { per } 1000\end{array}$ \\
\hline I & 172 & $0 \cdot 90$ & 155 & $0 \cdot 64$ \\
\hline TT & 391 & $2 \cdot 04$ & 483 & 1.98 \\
\hline BT & 178 & $0 \cdot 93$ & 227 & 0.93 \\
\hline $\mathrm{BL}$ & 51 & $0 \cdot 27$ & 63 & $0 \cdot 26$ \\
\hline LL & 139 & $0 \cdot 73$ & 120 & $0 \cdot 49$ \\
\hline Total & 931 & $4 \cdot 86$ & 1048 & $4 \cdot 30$ \\
\hline $\begin{array}{l}\text { Population } \\
\text { at risk }\end{array}$ & \multicolumn{2}{|c|}{191,444} & \multicolumn{2}{|c|}{243,787} \\
\hline
\end{tabular}

Table 6. Age and sex specific prevalence rates per 1000 in 1979 and 1983

\begin{tabular}{lcc}
\hline & \multicolumn{2}{c}{$\begin{array}{c}\text { Prevalence rate } \\
\text { per } 1000\end{array}$} \\
$\begin{array}{l}\text { Age and sex } \\
\text { group }\end{array}$ & 1979 & 1983 \\
\hline Male children & $2 \cdot 86$ & 3.34 \\
Male adults & $8 \cdot 89$ & 6.52 \\
Female children & $2 \cdot 26$ & $2 \cdot 70$ \\
Female adults & 4.36 & $3 \cdot 83$ \\
\hline Total & 4.86 & 4.30 \\
\hline
\end{tabular}




\section{Prevalence of disability}

Disability was assessed using the WHO criteria ${ }^{7}$ and for these analyses patients with only anaesthesia were excluded. At the end of the first survey there were 175 disabled cases giving a prevalence rate of 91.4 per 100,000 . The number of disabled cases in 1983 was calculated by adding those with disability detected during both surveys and then subtracting those who had died or emigrated (those whose disease was arrested but still had disability were not excluded). On this basis there were 153 disabled patients in the project area in 1983 giving a prevalence of $62 \cdot 3$ per 100,000 . The percentage of disabled cases in each classification is shown in Table 7 with the mean DI-2 values. The BL group have the highest percentage with disability and the highest mean DI-2 level but show little change between 1979 and 1983. The other types show a fall in the percentage disabled but little change in the mean DI-2 values.

Table 7. The percentage of patients with disability by classification.

\begin{tabular}{|c|c|c|c|c|c|c|}
\hline \multirow[b]{2}{*}{ Classification } & \multicolumn{3}{|c|}{1979} & \multicolumn{3}{|c|}{1983} \\
\hline & Number & $\begin{array}{c}\text { Disabled } \\
(\%)\end{array}$ & $\begin{array}{c}\text { Mean } \\
\text { DI }\end{array}$ & Number & $\begin{array}{c}\text { Disabled } \\
(\%)\end{array}$ & $\begin{array}{c}\text { Mean } \\
\text { DI }\end{array}$ \\
\hline I & 0 & - & - & 0 & - & - \\
\hline TT & 42 & $10 \cdot 7$ & $1 \cdot 15$ & 30 & $6 \cdot 2$ & $1 \cdot 17$ \\
\hline BT & 59 & $33 \cdot 1$ & $1 \cdot 68$ & 58 & $25 \cdot 6$ & $1 \cdot 52$ \\
\hline $\mathrm{BL}$ & 22 & $43 \cdot 1$ & $1 \cdot 72$ & 28 & $44 \cdot 4$ & $2 \cdot 03$ \\
\hline LL & 52 & $37 \cdot 4$ & $1 \cdot 59$ & 37 & $30 \cdot 8$ & $1 \cdot 62$ \\
\hline Total & 175 & $18 \cdot 8$ & $1 \cdot 53$ & 153 & $14 \cdot 6$ & $1 \cdot 57$ \\
\hline
\end{tabular}

\section{Discussion}

Leprosy control programmes using techniques of secondary prevention are employed throughout the world and although the details of the methodology may vary from place to place, they are similar in principle. It is important that such programmes are evaluated in terms of their outcome and not merely by measurements of input such as case detection rates. The objective of evaluation should be realistic to the methods used and an appropriate objective has been set out as the reduction progressively over a period of many years of the morbidity of leprosy to a level at which it no longer presents an important public health problem. ${ }^{8}$ Disability assessment is proposed as a relevant measure of leprosy morbidity. Thus a standard method of disability assessment ${ }^{7}$ has been used to evaluate a leprosy control programme. This evaluation required no additional resources other than that required to carry out the control programme. 
The advantages of this method of evaluation are that it is inexpensive, utilizes standardized methods and requires no additional staffing. The weakness of this method is that there is no control population with which to compare any changes in prevalence. The estimated population size required to have $90 \%$ power to detect a difference in prevalence at the $5 \%$ level is as large as the study population. The only feasible control for purposes of comparison is the general trend in leprosy and its disability in the neighbouring areas.

The demographic changes between the surveys are interesting and suggest that population growth is the result of births rather than migration or reduction in death rates. The examination rates were similar in both surveys although an improvement might have been expected as the programme became more established. The examination rates were highest in children and higher in women than men in both surveys.

The new cases detected in the second survey differed in type from those detected in the first survey. General house-to-house survey produced the majority of cases in both surveys but both school survey and contact surveillance became more valuable. The prevalence of leprosy in 1983 was very similar to that in 1979, there were more cases but the population examined had also increased. The prevalence of the various types of leprosy (Table 5) is interesting in that the prevalence of indeterminate (I) and lepromatous (LL) leprosy boih fell between 1979 and 1983. The I group probably fell due to patients completing their chemotherapy and becoming disease-arrested while the LL prevalence mainly fell through emigration and death. It is also interesting to note that the prevalence of leprosy in adults fell while that in children rose (Table 6). This may be explained by the fact that few children would complete their chemotherapy before the age of 15 years, or die, so that the number of cases increases with the increasing completeness of the survey; whereas the adult rates fell because of becoming disease-arrested, emigrating or dying. Most new cases in subsequent surveys will be in children since leprosy usually starts in childhood. ${ }^{9}$

Between 1979 and 1983 both the number of disabled leprosy cases fell and their prevalence rate despite the increase in total cases and the increase in the completeness of the examinations. The mean DI-2 values show little change between 1979 and 1983 in the severity of the disabilities.

Thus in the 4 years between 1979 and 1983 in a defined population, in which a leprosy control programme has been in action, there has been an increase in the total number of cases and little change in the disease prevalence. However, a fall in the number and the prevalence of disabled cases has been demonstrated. It is suggested that this decline in disabilities is an effect of the programme although without a suitable untreated control it is impossible to say whether this decline is part of a secular trend in leprosy. There is no evidence for such a secular trend of reduced disability in India. The mechanism of effect of the leprosy control programme on disease prevalence and disability prevalence is worth considering. Figure 1 demonstrates the changes in the prevalence of leprosy and suggests that 

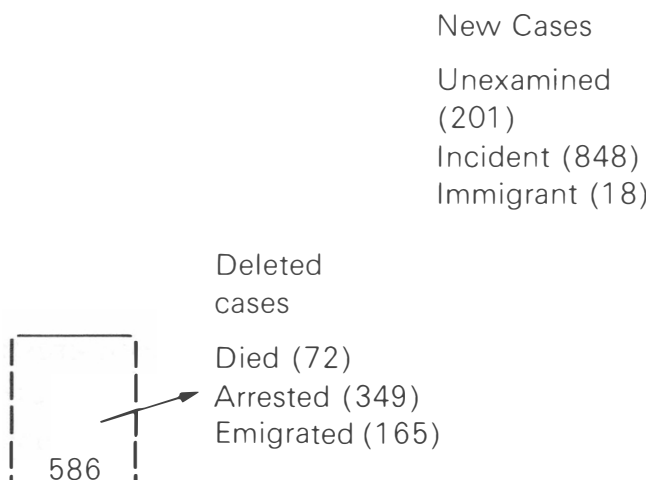

otal 931

1048

Population

at risk

Prevalence per 1000

Incident cases are new cases in individuals previously examined and found to be unaffected.

Figure 1. Change in the number of leprosy cases between 1979 and 1983 .

Number of disabled cases

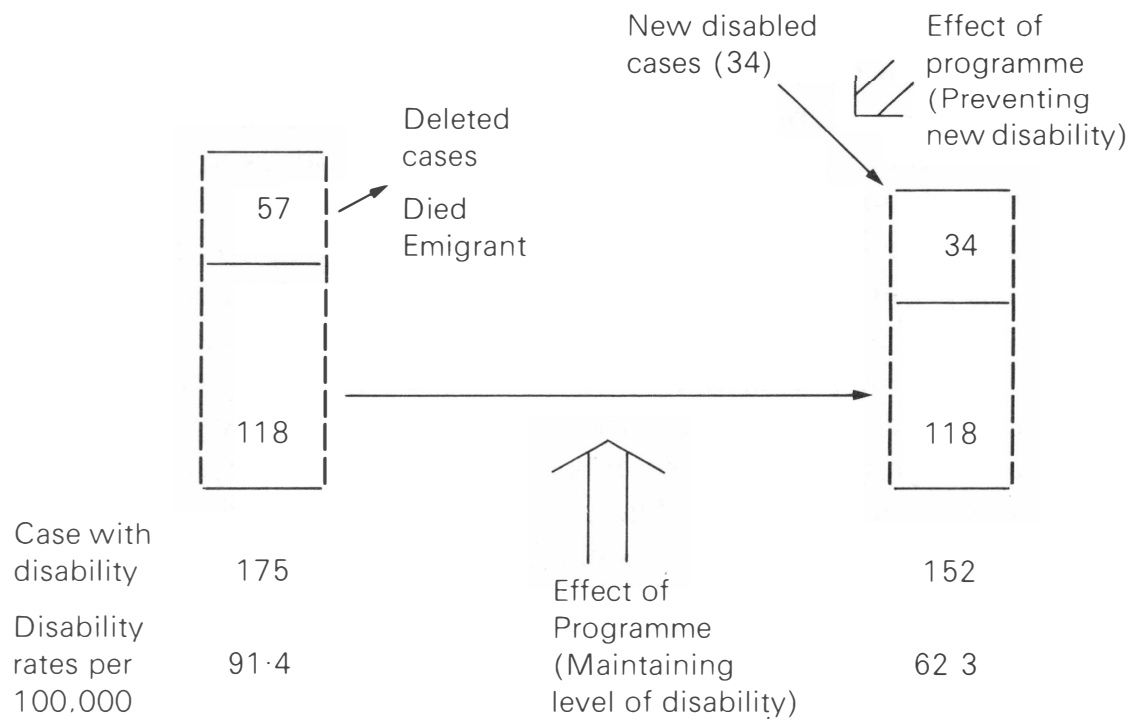

Figure 2. Change in the numbers of disabled cases between 1979 and 1983 
there has been little change in prevalence. Figure 2 shows, in a similar way, the changes in patients with disability due to leprosy. It is suggested that the main effects of the programme have been to slow the deterioration in those with existing disability and the prevention of new disability in patients with leprosy and no disability.

This form of evaluation is relevant and simple to incorporate into a control programme. It is proposed to re-examine the population in the same way at the end of the third survey.

\section{Acknowledgments}

We would like to thank all the staff of the Belgaum Leprosy Hospital and Leprosy Control Programme for their contribution to this ongoing work.

\section{References}

${ }^{1}$ Cochrane RG, Davey TF. Leprosy in Theory and Practice. John Wright and Sons Ltd. Bristol, 1964.

${ }^{2}$ Meade TW. Epidemiology and leprosy control. Lepr Rev, 1971; 42: 14.

${ }^{3}$ Crawford CL. The effect of outpatient DDS in an area of endemic leprosy. Lepr Rev, 1969; 40: 159.

${ }^{4}$ Sansarricq H. Leprosy in the world today. Lepr Rev, 1981; 52 (Suppl 1): 15.

${ }^{5}$ Smith WCS, Antin US, Patole AR. Disability in leprosy: a relevant measurement of progress in leprosy control. Lepr Rev, 1980; 51: 155.

${ }^{6}$ Government of India. Guidelines for the National Leprosy Control Programme.

7 Bechelli LM, Dominguez VM. Disability index for leprosy patients. Bull WHO 1971; 44: 709.

${ }^{8}$ Bechelli LM. Evaluation of leprosy control programmes-some suggestions for operational and epidemiological assessments. Bull WHO 1970; 42: 631.

9 Noussitou FM, Sansarricq H, Walter J. Leprosy in children. World Health Organisation. Geneva, 1976. 